\title{
Going Online: The Affordances of Online Counseling for Families Affected by Alcohol and Other Drug Issues
}

\author{
Ella Dilkes-Frayne ${ }^{1,2}$ (D) Michael Savic ${ }^{1,3}$, Adrian Carter ${ }^{1,4}$, \\ Renata Kokanović ${ }^{5}$ (D), and Dan I. Lubman ${ }^{1,3}$
}

\begin{abstract}
Online counseling can overcome barriers families face when accessing support services for issues such as a relative's alcohol or other drug use. However, little research has explored how online counseling platforms assist family members to improve their well-being and support their relative. We thematically analyzed 90 transcripts of online counseling sessions with family and friends of people who use alcohol, opioids, and amphetamines in Australia between 2015 and 2016. In our analysis, we drew on the concept of affordances to articulate how online platforms afford or constrain potentially therapeutic encounters with families. We found online counseling enabled families to make first contact, relieve distress, plan appropriate action, improve communication, regain direction, and connect with local services. Sessions were constrained by Internet access, web-chat communication, counselors' focus on referral, and limitations in addressing the wider concerns of families. The findings present opportunities for improving online services for families.
\end{abstract}

\section{Keywords}

addiction; affordances; alcohol and other drugs; Australia; e-mental health; families; Internet; online counseling; qualitative

\section{Introduction}

Online web-chat counseling is being increasingly utilized for the provision of support and treatment to people experiencing issues with mental health, gambling, addictions, and a range of other issues (Dowling \& Rickwood, 2013; Gainsbury \& Blaszczynski, 2011; Rodda, Lubman, Dowling, \& McCann, 2013b; Sucala et al., 2012). Although services tend to target the person who is experiencing the issue, many services also provide support for their families and friends. Families have specific support needs that may differ from others seeking support (Wilson, Rodda, Lubman, Manning, \& Yap, 2017b); however, less research has focused on how online counseling serves families' needs in particular. In this article, we use online alcohol and other drug counseling as an empirical example to explore how the features of online counseling platforms can support families seeking help online or constrain opportunities for support.

Families are often an important source of support and connection for people having issues with alcohol or other drug consumption and can be a motivating factor in people seeking treatment (Adams, 2007; Wagner et al., 2017).
However, the strains placed on these relationships can affect the health and well-being of family members (O'Grady \& Skinner, 2012; Orford, Copello, Velleman, \& Templeton, 2010a). Families can experience relationship difficulties, conflict over money and possessions, uncertainty about family life, mistrust, and occasionally, aggression and violence (McCann, Lubman, Boardman, \& Flood, 2017). Although family members use varied informal strategies to maintain their own and their relative's well-being, professional support services are often necessary (Orford, Velleman, Copello, Templeton, \& Ibanga, 2010b).

\footnotetext{
'Monash University, Clayton, Victoria, Australia

${ }^{2}$ The Australian National University, Canberra, Australian Capital Territory, Australia

${ }^{3}$ Eastern Health, Melbourne, Victoria, Australia

${ }^{4}$ The University of Queensland, Herston, Queensland Australia

${ }^{5}$ RMIT University, Melbourne, Victoria, Australia

\section{Corresponding Author:}

Ella Dilkes-Frayne, School of Sociology, Research School of Social Sciences, The Australian National University, Building 22, Haydon Allen Building, Canberra, Australian Capital Territory 260I, Australia. Email: ella.dilkes-frayne@anu.edu.au
} 
A wide range of support services are available to families including telephone support lines, family peer support groups, online resources, workshops, information sessions, and individual, couple, or family counseling. Despite this, families often have difficulty accessing formal services or being involved in their relative's treatment (McCann et al., 2017; Misouridou \& Papadatou, 2017). This difficulty can be caused by a lack of local availability or knowledge of services, existing services being targeted toward people who use drugs rather than their families, or a reluctance to seek support due to shame, fear, and the stigma surrounding addiction (Copello \& Orford, 2002; Frye, Dawe, Harnett, Kowalenko, \& Harlen, 2008; McCann \& Lubman, 2017a, 2017b). Online services have been suggested as an effective means to overcome access barriers and provide brief, cost-effective interventions to families (Copello \& Templeton, 2012; McCann \& Lubman, 2017a; O'Grady \& Skinner, 2015; Wilson, Lubman, Rodda, Manning, \& Yap, 2017a; Wilson et al., 2017b).

Online alcohol and other drug counseling (henceforth referred to as "online counseling") originated as a lowcost early intervention aimed at removing barriers to access and facilitating timely referral to treatment for people who use alcohol and other drugs. Although many online counseling services also target family and friends, much of the research literature focuses on its utility for those seeking support for their own drug use. Online counseling differs from face-to-face counseling in that it involves a text-based real-time web chat with a counselor and often takes place in a short one-off session. Previous research has indicated that many people who use online counseling prefer it to telephone or face-to-face counseling because they can access it anonymously (unless they choose to disclose their identity or register for ongoing contact), discreetly, and at a convenient time and place (King et al., 2006; Rodda, Lubman, Dowling, Bough, \& Jackson, 2013a; Rodda et al., 2013b). Its immediacy works with people's fluctuating motivations for seeking support, enabling them to inquire about other treatment options, improve their well-being and reduce distress (Copeland \& Martin, 2004; Dowling \& Rickwood, 2013; Gainsbury \& Blaszczynski, 2011). Online counseling also has the potential to reach people who require assistance outside business hours due to the time constraints of work or child care responsibilities, who prefer text-based communication, or who are reluctant to seek in-person support due to stigma, safety concerns, and the risk of involvement of child protection (Garde, Manning, \& Lubman, 2017; King et al., 2006; Swan \& Tyssen, 2009). Although some online counseling services are primarily intended to provide brief information, support and referral, it is now well established that many people seek support online as a treatment in its own right, without the desire to access other face-to-face services (Rodda,
Lubman, Cheetham, Dowling, \& Jackson, 2015; Savic et al., 2018).

Research has suggested that a therapeutic alliance between counselor and client, similar to face-to-face or telephone counseling, can occur in online counseling (Richards \& Viganó, 2013; Sucala et al., 2012). However, text-based communication can make it difficult to determine the extent of a client's distress and increase the possibility of misunderstandings and miscommunication due to the absence of nonverbal cues (e.g., gestures, facial expressions) and the difficulty of capturing the subtleties of sarcasm, humor, or nuanced inferences (Bambling, King, Reid, \& Wegner, 2008; Barak \& Bloch, 2006; Chardon, Bagraith, \& King, 2011). Exchanges are also limited by typing speed and written language ability, and less content is generally shared in an hour of online counseling than an hour of face-to-face counseling (Day \& Schneider, 2002). Online sessions also tend to be shorter than face-to-face counseling, often with limited opportunity for follow-up sessions. This can result in a focus on history-taking, client story-telling, information gathering or rapport building, while limiting the time for exploring goals and developing strategies for action (Chardon et al., 2011; Rodda et al., 2015; Williams, Bambling, King, \& Abbott, 2009). Time constraints during the counseling session can lead counselors to focus narrowly on alcohol and drug-related concerns at the expense of more complex psychosocial issues (Savic, Ferguson, Manning, Bathish, \& Lubman, 2017). Furthermore, where clients are dissatisfied with the counseling they receive or with the constraints of the online platform, they can simply "drop out" of counseling and be difficult to reconnect (Stommel \& van der Houwen, 2014).

Research into the potential and limitations for online counseling has, however, rarely focused on the provision of support to family members, despite research finding that around one in 10 people who access an online counseling service in Australia were family members (Garde et al., 2017). In their study into partners who accessed online alcohol and drug counseling, Wilson and colleagues (2017a) found that partners had experienced a range of barriers to face-to-face support, and primarily came online because they wanted to talk about their concerns, and receive advice on how to provide support for their partner, practice self-care, or access other formal treatment services for themselves or their partner. Online counselin was often their first time seeking formal support and was a promising way of identifying pressing needs and acting as a referral pathway through a brief and immediate intervention. However, more research is needed in this area.

In this article, we seek to contribute to addressing this gap by examining how specific features of online counseling may assist family members to reduce distress, 
practice self-care, and better support their relatives. Using an empirical example from our study of alcohol and other drug counseling, we explore the technological and social "affordances" of an online counseling platform to consider what action possibilities online counseling provides to family members, particularly those affected by a relative's alcohol or other drug consumption.

Technological affordances represent the potential that technologies hold for enabling human action. James Gibson (1979) first wrote about affordances in the context of ecological psychology, with regard to how environments offer or "afford" animals opportunities for posture, movement, and behavior. An affordance was not considered to be a physical property of an environment, but the particular action or constraint a feature might provide to a particular animal. Donald Norman (1988) later popularized the idea of affordances in relation to humancomputer interactions and saw affordances as "designedin" properties of objects that signal to the user what the technology could be used for. In alcohol and other drug studies, the notion of affordances has been used to explore how agency, sociality and morality are collectively performed through technologies, objects, and environments (e.g., Fraser, Treloar, Gendera, \& Rance, 2017).

In this article, we take up a socio-material approach to affordances whereby an affordance is seen as neither a property of an object or environment, nor the result of human agency and mastery; rather, an affordance emerges through the imbrication of human and material agencies that unfold in the encounter between them (Bloomfield, Latham, \& Vurdubakis, 2010; Chemero, 2003; Hutchby, 2001). The affordances of a particular technology offer are thus dynamic, as a technology will not afford the same action to all who encounter it (Bloomfield et al., 2010; Davis \& Chouinard, 2017; Hutchby, 2001; Klinke, Thorsteinsson, \& Jónsdóttir, 2014). It is, therefore, necessary to consider in what circumstances a technology affords action, and the constraints a particular situation might pose to limit these possibilities. Such a consideration must take into account the ways in which humans and technologies come together to give rise to or constrain the affordances produced.

In this article, we focus on the opportunities for action various features of online counseling afford to families and consider the situations in which these affordances are constrained, limiting their potential to meet families' needs. To do so, we share findings from our research, which aimed to explore the experiences of family clients accessing online counseling to identify ways in which online services could be adapted to better meet their needs. The study involved qualitative analysis of transcripts of online counseling sessions with family members in Australia and descriptive statistical analysis of accompanying demographic data and session details. Our analysis in this article centers around one theme from our study, and uses the concept of affordances to explore how key features of the online platform enable and constrain families to seek and obtain assistance and support. To conclude, we discuss how online counseling services may be improved to better meet the specific needs of families.

\section{Method}

We analyzed 90 transcripts of online counseling sessions with family members and friends contacting an Australian 24-hour real-time web-chat alcohol and other drug counseling service, Counseling Online. The counseling service aims to provide brief intervention with the provision of information, support, and referral for people who use alcohol or other drugs and their family and friends. The counselors come from a range of backgrounds including psychology, social work, nursing and welfare studies, and receive specialized training in alcohol and drug treatment. Counseling follows motivational interviewing techniques, including reflective listening, expressing nonjudgment and empathy, open-ended questioning, development of a therapeutic alliance, exploring beliefs and experiences, and proposing solutions (Miller \& Rollnick, 1991). At the time of data collection, the service did not provide counseling in any languages other than English.

\section{Data Collection}

We requested 90 deidentified transcripts and accompanying demographic data from Turning Point, the organization that operates the service, in accordance with the ethics approval granted by Eastern Health (Application LR53-1112) and Monash University Human Research Ethics Committees (Project 8685). Individuals provide consent prior to the counseling session for the transcript of the session and a brief demographic questionnaire to be saved and used for quality assurance and research purposes. Data pertained to sessions taking place between January 2015 and December 2016. The sample of transcripts included both male and female clients, from all age ranges, who identified their relationship to the person of concern as "partner," "son or daughter," "parent," "sibling," "other relative," or "friend." Our research included only transcripts involving alcohol, amphetamines, or opioids as the primary drug being used by the relative, as these are three of the drugs for which people commonly access the service (Garde et al., 2017). The demographic data included responses that people provided prior to the start of their counseling session, including their age range, gender, location, country of birth, preferred language, sexual orientation, and prior use of formal services, as well as data noting the date of contact, and the time the session began and ended. 


\section{Data Analysis}

We conducted descriptive statistical analysis of the demographic data for the 90 clients included in the sample to identify the frequency of age, gender, location, country of birth, sexual orientation, and prior use of formal services. We calculated the duration of sessions from the session start and end times and calculated the mean session duration for men and women.

Counseling transcripts were imported into NVivo 10 software for coding and management. Qualitative analysis of the transcript data was guided by the following research questions:

Research Question 1: Why do family members engage with online counseling and what do they hope to achieve?

Research Question 2: What are their experiences of online counseling?

Research Question 3: How could the service be improved to better meet their needs?

Initial coding of the data followed an inductive approach outlined in Braun and Clarke (2006), whereby data were coded without a pre-existing coding frame based on a particular theoretical approach. In line with methods for establishing rigor in qualitative research (Barbour, 2001), after initial coding of 20 transcripts by Ella Dilkes-Frayne, a subset of transcripts was provided to three of the research team members to cross-check the coding strategy and data interpretation. Several codes were added and minor adjustments made. The subset of transcripts was then re-coded and the remaining transcripts coded by Ella Dilkes-Frayne. Following this process of generating initial codes, preliminary themes were identified on the basis that they "capture[d] something important about the data in relation to the research question" (Braun \& Clarke, 2006, p. 82). The codes and preliminary themes were then discussed among the research team, resulting in codes and themes being refined based on the developing areas of analytic interest.

One theme identified that was central to our research question was "the online counseling platform." We focus only on this theme in this article. This theme included codes capturing the features of the online counseling platform and how these features informed how counseling sessions unfolded. Four main features of the platform were identified as particularly salient in the data: (a) immediate, 24-hour access from anywhere; (b) written, web-chat communication; (c) being a broad, yet targeted service; and (d) time with a trained counselor. When analyzing how these features influenced counseling sessions, the research team felt the concepts of affordances and constraints (Bloomfield et al., 2010; Davis \& Chouinard, 2017) helped to articulate what we were seeing in the data regarding how the platform enabled or constrained counselors in supporting clients. We then read the data in this theme through the lens of "affordances" and present our analysis below.

The cases that follow were selected on the basis that they provided rich and illustrative examples of the affordances and constraints of the online platform for counseling clients. We focus our qualitative analysis on the data from immediate and extended family members only $(n=$ 76), although the concerns raised are relevant to friends who access to the service, and in many cases, people who access the service for support with their own consumption or abstinence. In reporting quotes from these exchanges, we have edited the text to improve clarity and correct misspelled words where errors affect the meaning of the exchange. To protect participant anonymity, all names that appear are pseudonyms. Any edits in quotations are marked with square brackets. Otherwise, the quotes appear verbatim, with errors shown as they appeared in the original transcript to maintain fidelity to the web-chat communication form.

\section{Results}

\section{Sample Demographics and Session Duration}

The demographic characteristics of our sample are summarized in Table 1. Overall, our sample was $60 \%$ female and predominantly born in Australia and heterosexual. The majority were using the service as their first time seeking help and over half (56\%) were partners of someone whose drug use motivated contact with the service. The average duration of sessions was 47 minutes, with women having a significantly higher average duration (53 minutes) than men (37 minutes). These data were not drawn from a representative sample of online counseling users, and, therefore, cannot be generalized to the service on the whole; they are listed here only to provide a snapshot of the demographics of our sample for the qualitative analysis that follows.

To provide an in-depth account of how various features of the online counseling platform afforded and constrained the service's ability to support family members, we now turn to the qualitative data from counseling sessions. The analysis that follows is organized around four main features of the platform-(a) immediate, 24-hour access from anywhere; (b) written, web-chat communication; (c) being a broad, yet targeted service; and (d) time with a trained counselor - and the affordances and constraints associated with each.

\section{Immediate, 24-Hour Access From Anywhere}

The counseling service is available 24-hours a day, 7 days a week, with no appointment or waiting list. The majority 
Table I. Sample Demographic Characteristics $(n=90)$.

\begin{tabular}{|c|c|c|c|}
\hline Category & Characteristic & Number & $\%$ \\
\hline \multirow[t]{2}{*}{ Gender } & Female & 54 & 60 \\
\hline & Male & 36 & 40 \\
\hline \multirow[t]{6}{*}{ Age range (years) } & $15-19$ & 3 & 3 \\
\hline & $20-29$ & 28 & 31 \\
\hline & $30-39$ & 31 & 34 \\
\hline & $40-49$ & 18 & 20 \\
\hline & $50-59$ & 8 & 9 \\
\hline & $60+$ & 2 & 2 \\
\hline \multirow[t]{2}{*}{ Country of birth } & Australia & 78 & 87 \\
\hline & Overseas & 12 & 13 \\
\hline \multirow[t]{2}{*}{ Preferred language } & English & 89 & 99 \\
\hline & Mandarin & I & I \\
\hline \multirow[t]{9}{*}{ Location (state) } & $\mathrm{ACT}$ & I & I \\
\hline & NSW & 14 & 16 \\
\hline & NT & I & I \\
\hline & QLD & 22 & 24 \\
\hline & SA & 16 & 18 \\
\hline & TAS & I & I \\
\hline & VIC & 29 & 32 \\
\hline & WA & 5 & 6 \\
\hline & Invalid & I & I \\
\hline \multirow[t]{3}{*}{ Sexual orientation } & Heterosexual & 81 & 90 \\
\hline & LGBTIQ+ & 6 & 7 \\
\hline & Prefer not to say & 3 & 3 \\
\hline \multirow[t]{2}{*}{ Obtained previous help from any source } & No & 53 & 59 \\
\hline & Yes & 37 & 41 \\
\hline \multirow[t]{6}{*}{ Relationship to person of concern } & Partner & 50 & 56 \\
\hline & Son or daughter & 5 & 6 \\
\hline & Parent & 9 & 10 \\
\hline & Sibling & 9 & 10 \\
\hline & Other relative & 3 & 3 \\
\hline & Friend $^{\mathrm{a}}$ & 14 & 15 \\
\hline
\end{tabular}

Note. LGBTIQ = lesbian, gay, bisexual, transgender, intersex, and queer.

${ }^{a}$ Not included in qualitative analysis presented in this article.

of family members in this sample (66\%) initiated contact outside of standard business hours (9:00 a.m.-5:00 p.m.), with the vast majority of these out-of-hours sessions taking place in the evening hours after 5 p.m. This indicates that the service was utilized by family members mostly at times when other services were unavailable. Although people did not always state where they were contacting from, for those who contacted during standard business hours, some indicated that they were at work at the time, or contacting between other commitments such as child care. The immediacy of access at any time and location afforded family members discreet access to support, at a time that was convenient, or when the issue was particularly high in their minds.

For example, a woman in her late 40 s contacted the service at 8:43 p.m. to discuss her concerns about her partner's drinking. Early technical issues upset the flow of communication, but these were soon resolved.

Client: cant see what I'm typing, a glitch with the window maybe

Client: sorry so slow

Counsellor: I can see what you are typing from this end, would you rather call and speak to someone? I can look up the number for your local service [...]

Client: [My partner] is drinking at least a dozen beers nearly every night

Counsellor: does your partner feel that their drinking is a problem? what worries you more about his drinking? [...]

Client: his behaviour: he gets nasty and reckless with me and our son [...] 
Client: my partner doesn't know I'm talking to you and I'd rather he didn't hear me

Counsellor: that's ok, i'm happy to keep talking here, when your husband is nasty do you ever feel unsafe?/has his drinking ever caused any injury? $[\ldots]$

Client: yes unsafe, only himself so far [. . .]

Counsellor: Do you have a safety plan in place if you need to leave?

Client: This is it unfortunately [. . I have several disabilities and] The man is my carer [...]

Client: im going to need help. To make a plan [. . .] And this is already helping :) [ ...]

Counsellor: I'm glad you feel comfortable talking here about what is going on, you can contact anytime

The conversation continued for nearly an hour and a half, during which the client aired her fears that her partner's drinking and behavior toward her would never change, and what he would do to her, himself, and their son if she left him. The counselor sought to reframe the issue not as the client's personal weakness, as she had described it, but her partner's lack of willingness to change or see her point of view, and as an issue of her and her child's safety. During the exchange, the client decided, with the counselor's encouragement, to see her GP and asked to be referred to face-to-face counseling where she could make a clear plan for dealing with the situation. The client expressed her gratitude for the advice, saying "I've thought for so long and this is the first time I've said [these thoughts. . .] Thank you so much [. . .] I'm breathing a little easier :)." Although the web-chat platform caused some difficulties initially, the technical difficulties were bound up with the affordances; the same features that caused issues afforded her the ability to discreetly get support in the presence of her partner, in the evening hours when he often drank, via a platform she could access with her disabilities. As the client noted, the contact enabled her to express thoughts she had previously kept to herself and make a plan for the next step to take, relieving some of her distress.

The immediacy of the service appeared particularly useful for family members contacting the service at times of heightened emotional distress. A woman in her late $20 \mathrm{~s}$, for example, contacted the service in the early hours of the morning ( 2 a.m.) looking for some support when she felt she had nowhere else to go.

Client: My partner drinks quite a lot on the weekends and makes poor decisions occasionally using methamphetamine [. . .] I'm really worried about him but I don't know how to help him while he doesn't think he has a problem [...He is] in the other room using with a friend, it honestly hurts so much [...] I just don't know what to do next
Counsellor: [. . .] from your conversations with him before I get the impression he does not want to hurt you - but is not ready to stop how he is living at the moment, there are no easy answers, you need to decide what you are ok with and not ok

Client: [. . .] Perhaps I'll make arrangement to come home on Monday and talk about it then when he is sober. That will give me some time to think about what I want and how to talk about it

Counsellor: breathing space may be a good idea to figure things out a bit more - don't put pressure on yourself to have all the answers tonight [ . . ]

Client: Thankyou, I'm definitely too anxious and upset to sleep so Ill focus on that for now and use the day tomorrow to get out and about to think

The client and counselor spoke for almost an hour. Being able to contact the service out of hours, while in the house with her partner, but without his knowledge, at a time when she was distressed and feeling out of options, afforded the client the opportunity to express her thoughts, receive support, and decide how to address her concerns in the light of day once her partner had sobered.

As can be seen in the previous two cases, having immediate, 24-hour access from anywhere afforded these clients their ability to make first contact with services, at a time of heightened concern, when little else was available or suitable. The immediate support could relieve their distress and help them work through their options for moving forward. These affordances were, however, constrained by Internet access and platform compatibility issues, which occasionally upset the flow of communication. Because counselors worked on rotating shifts across a 24-hour period, people could recontact the service multiple times, but they were unable to contact the same counselor for ongoing support. Counselors often invited people to contact the service again at a later date to encourage families to remain in contact with the service; however, they also recognized the limitations of the platform and referred people to face-to-face services for long-term support. Similarly, the service could be contacted at any time, leading some family members to contact at a time of crisis, however, due to the anonymity of the service, it was unable to provide significant crisis support, and in these cases, people were referred to telephone crisis support services or police.

\section{Written Web-Chat Communication}

As seen in the cases above, one important affordance of communicating via text was discreetness when contacting in the presence of their relative. Written communication also afforded a number of other actions and posed some constraints. For some, the written communication facilitated disclosure and discussion about an issue they 
had found difficult to speak about "out loud." For example, a young woman in her early 30 s contacted the service for advice on how to help her boyfriend with his methamphetamine (ice) use.

Client: I was seeing a guy for around 3-4 months [. . .] He started to telling me a lot of things, which he was hiding and didnt share with anyone [. . .] He told me that he had [ice] couple of times and starts to feel that he needs help, but doesnt know where to start [. . .] I don't know who to tell [. . . I] am so happy for this online service

The client and counselor discussed the client's concerns, whether her boyfriend would consider seeking support, and the counselor affirmed that she was approaching the situation in an appropriate way before referring her to her local alcohol and other drug information service (telephone helpline) for more details on local services. At the conclusion of the session, the client expressed her gratitude for the service, particularly that it was text-based.

Client: Thank you very much for your help [ . . . I feel so much better and relaxed [. . .] I needed to share this with someone and get some understanding [...] I was thinking first that I will call, but it was too difficult, if I would actually have to speak, it is so much easier to text it.

In this client's case, the service's written web-chat feature was important in her feeling comfortable to share her experiences and concerns, and, as for many others, facilitated her contacting a service for the first time. Communicating via text also provided the opportunity for people who had registered for the service to save their chat session to revisit later, which some expressed as a desirable feature.

However, communicating via written web chat did not always afford smooth communication.

Numerous clients had difficulty seeing their messages due to issues on mobile devices or with Internet connectivity. When people wrote either a number of short messages in quick succession or appeared to be inactive while writing a very long message, this could disrupt the flow of communication. Communication problems could also originate from the counselor when they asked a number of questions at once. In another client's session, for example, the counselor communicated the need to "take it in turns" for the communication to work best.

Counsellor: Hello—-how may I help you?

Client: i just needed to chat to an outside person about some things im feeling tonight i guess [.. .] im feeling anxious tonight because [my partner] has been doing quite well with her addiction lately but a couple of lapses over the past couple of weeks

Counsellor: Please tell me more about the situation. How old is she-and you? How long have you known one another?

Client: $\mathrm{i}$ try to be understanding but $\mathrm{i}$ do tend to get very upset (as in emotional, not angry really), and it makes it worse for her, and so because of this the last couple of times she stopped telling me as we agreed for her to be honest when she uses ....

Client: we are both 32 and been together only 6 months

Counsellor: This chat works best if we "take-it-inturns"-is that OK with you?

Client: yep :)

In some cases, people receiving counseling appeared to disconnect suddenly when they were unable to develop smooth communication. For some, having to express complex concerns in detail was more challenging on the online platform. This sometimes resulted in family members taking a long time to respond when detailing their story, which in turn often resulted in counselor uncertainty about whether the client was still connected and difficulty addressing all of the issues raised. In some cases, the platform did not appear to be the most appropriate avenue of support, necessitating referrals to other services that would better suit people's needs, but that were not necessarily accessible at the time of contact.

\section{Broad, Yet Targeted Service}

The counseling service is funded on the basis that it provides targeted alcohol and other drug counseling, however, the service also allows for broad intervention as it invites people to contact a counselor with any issue related to alcohol and other drugs. Following motivational interviewing techniques (Miller \& Rollnick, 1991), counselors take the needs and concerns of the person contacting the service as the starting point for the session. For families, the breadth and flexibility can be beneficial as the concerns they have vary considerably. However, the targeting can be a constraint when concerns are complex, varied, and not limited to alcohol and other drugs.

As some of the cases discussed above have shown, many family members contacted the service as a result of the impact their relative's alcohol and other drug use had had on their relationship. The counseling often focused on managing conflict, communication strategies, maintaining or ending relationships, and developing self-care strategies. One client, for example, was a mother whose son had been consuming methamphetamines since his late teens and had been experiencing significant mental health issues. She contacted the service looking for support with the impact her son's drug use had on her relationship with 
her husband and her mental health, which also involved issues beyond her son's drug use.

Client: Hi, I'm really here because I'm struggling massively with my own mental state due to my sons drug addiction which has led to huge marriage problems between me and his dad [...] I'm not sure if I' $m$ in the right place to discuss marriage and personal issues I have also

Client: I need help in all areas

Counsellor: to an extent it is the right place but in the context of his drug use

Although the counselor clarified that the service was targeted at alcohol and other drug use, and the concerns they discussed would need to be addressed in that context, the service was flexible enough to allow for a broad discussion of the history of her son's drug consumption, the impact it had had on her relationships with her immediate and extended family, mental health and employment, and to get suggestions for how to deal with it. The client chatted with the counselor for over an hour and a half and the counselor provided strategies for coping and self-care.

Other sessions were undermined by the service being targeted toward alcohol and other drugs in cases where family members were seeking broader support or where the counselor was unwilling or unable to discuss matters that they did not see as directly related to alcohol and other drug use. This was particularly important for women contacting the service who were experiencing domestic violence. Although some counselors were adept at dealing with abusive partners and domestic violence, others were less so. The most common advice was to call the police. Referrals to domestic violence services were only occasionally provided. For example, a man in his late 30 s contacted the service to discuss his father's drinking and abusive behavior, but in this case, the counselor was reluctant to provide advice on anything other than his father's alcohol use.

Client: hello. I'm having a problem with my father

Counsellor: hello what is going on with your father?

Client: he's really unstable and verbally abusing people

Client: he treats me and my brother fine, but we are about the only exceptions

Client: nearly everyone else, including mum, is getting treated very badly

Client: i'm not sure how to help him

Counsellor: does he have issues with substances? as I can only really assist you with that

Client: he's drinking a lot
Client: 1-2 litres of cask wine per day [. . for] at least 5-10 years [. . .] worse lately, there are some family issues, he's not coping [. . .] he says he's fine and he's allowed to enjoy himself

Counsellor: so he is not interested in getting help by the sounds of it

Client: nope. I don't think he would acknowledge there is a problem. and it's hard to have a conversation with him, he doesn't listen [. . .] but i'm quite worried about my mum, so I need to do something now [...] any suggestion how I should approach him?

Counsellor: ok then I'm not sure of this as he does not want to change his drinking and it seems you are more concerned about his behaviour to family members which is not something I feel that I can help you with

In contrast to the first case presented in this section, the latter client was not offered communication strategies, relationship advice, or information on where to refer his father, limiting the opportunity for him to work through his concerns and decide on an appropriate next step to support his parents or encourage his father to address his drinking or behavior. After 25 minutes, the client disconnected from the service suddenly. Although it was not evident in all cases, it appears that this particular counselor either felt unqualified to provide appropriate advice, or that the counselor felt it was not the role of the service to provide it, limiting the service's affordances for this client.

It is, of course, necessary for counselors to be clear about their training and what they can or cannot provide support with, however, alcohol and other drug issues crosscut with many other issues, particularly for families. There were several other examples in which people came to the service looking for varied advice, but were told the service was unable to address their needs. Other concerns raised included family members' own mental and physical health concerns, legal issues, and contact with police, specific medical advice around pharmacotherapy, child protection and child custody, financial issues, and requests about information around car interlocking devices and home drug testing kits. This reflects the diversity of the issues people are facing related to alcohol and other drug use in the family. Addressing these complex issues requires service funding that can equip counselors with skills to deal with a wide range of concerns, and knowledge of referral pathways into a wide range of sectors, to provide appropriate outcomes for families.

\section{Time With a Trained Counselor}

As several of the previous examples have shown, one of the key features of the service is enabling time with a trained 
counselor, which afforded family members a number of benefits, particularly if a good flow of communication was established. One client, a man in his late 20 s, contacted the service about his brother's heroin use, writing that he was "worried about a full blown relapse and what it will do to him and the family." Over the course of the session, he and the counselor discussed how and when the client could approach his brother to express his concerns.

Counsellor: I think you might need to talk with him [. . .] about his behaviour, anything you have noticed, we use "I statements" instead of you as that sounds more accusatory [. . .] perhaps suggest what you have said to me just then, you seem [fine] but I'm not sure you are [...]

Client: That's a good starting point I think. But do you think I should wait a week or 2 before I say anything. As if I bring it up now seemingly out of the blue $[\ldots]$

Counsellor: it might be better to wait so that you can also plan what you want to say, he might very well shut you down but all you can do is try, he will talk when he is ready

Client: Thanks for the advice

For this client and many others, having time to discuss concerns with a trained, nonjudgmental and understanding counselor afforded the opportunity to share their histories, air grievances, express fears, and ask for assistance. In these discussions, counselors provided affirmation of their efforts, support in their struggles, reframed the concern with their understandings of addiction, talked through communication strategies, helped to plan a course of action, or link people with local services. Family members often expressed that these conversations had relieved their distress, or given them a greater sense of direction and control.

However, counselors were not always understanding of families' needs or concerns, or able to allow people to use the session as a place to simply vent their feelings or tell their stories. In a number of instances, due to the intention of the service to provide a brief intervention, counselors appeared focused primarily on providing the most appropriate referral to face-to-face services, rather than engaging in extended counseling, and many sessions concluded soon after a referral was provided. Overall, however, many family members expressed their gratitude at having been treated with openness and without judgment, and at having a space to which they could return when they needed further support.

\section{Discussion}

In this article, we aimed to contribute to the research literature regarding how online counseling can be used to meet the needs of families seeking support. Drawing on the concept of technological affordances, which lie in the collective relations between individuals and technological platforms, we identified a number of ways in which online counseling was beneficial to family clients, as well as ways online services could be enhanced to improve access and better deal with families' concerns.

Our research identified similar benefits for families accessing online counseling as found in previous research with different populations. Online counseling can overcome many of the structural and social barriers, including stigma, that discourage family members from accessing formal services and provides a new and important avenue for support and connection (Copello \& Orford, 2002; Frye et al., 2008; McCann \& Lubman, 2017a, 2017b) The immediate availability of an online service, 24 hours a day, enabled families to make contact at a convenient time and place, in times of heightened concern or when motivated to seek assistance (King et al., 2006; Rodda et al.,2013a; Rodda et al., 2013b; Swan \& Tyssen, 2009). That many contacted the service out of standard business hours when little else was available, and that it was the first point of contact with formal support services for most, highlights the utility of online counseling for connecting with new populations and facilitating referral (Garde et al., 2017; Wilson et al., 2017a; Wilson et al., 2017b).

For those who were proficient with communication in written English, the online platform allowed them to express concerns and emotions that they had found difficult to verbalize, and also afforded a discreet way to seek assistance in the presence of the person they were concerned about. Family members were generally able to discuss a wide range of concerns, reframe the issue in productive ways, develop communication strategies, and link with local services. These outcomes could relieve distress, help them plan a course of action, regain a sense of direction and control, and to simply have a nonjudgmental space and an understanding ear at a time of need. Our findings thus support previous research suggesting that when communication runs smoothly, effective support and counseling can be achieved (Richards \& Viganó, 2013; Sucala et al., 2012).

These affordances, however, were not always realized, in line with the suggestion that technologies cannot be assumed to afford the same possibilities to all people who use them in all circumstances (Bloomfield et al., 2010; Davis \& Chouinard, 2017). Consistent with previous research, the therapeutic alliance formed was limited by a person's proficiency with the web-chat platform and written communication (Day \& Schneider, 2002; Richards \& Viganó, 2013; Sucala et al., 2012). A stable Internet connection, a compatible device, and comfort with written web-chat communication were essential for setting up a productive flow to the exchange. Communication issues, 
such as overlapping and confusing exchanges, disrupted the ability of some family members and counselors to connect with one another. Similarly, the context in which the family member and counselor were at the time could limit the duration, pace and depth of the conversation, suggesting a need for further research into the contexts in which people access online services, and in which counselors are tasked with responding.

It is evident that communicating complex issues via online web chat is not well suited to all people seeking support. The majority of clients in our sample were born in Australia, with nearly all listing English as their preferred language, suggesting the service could improve its reach with people from culturally and linguistically diverse communities. The counseling service we studied did not provide counseling in languages other than English at the time of the study. Although few online services in Australia provide counseling in other languages, many online services are partnered with telephone services that can be used in conjunction with a translation and interpreting service. Even so, a lack of counseling in multiple languages is a significant limitation, as there is unmet need for prevention and treatment for alcohol and other drug issues among culturally and linguistically diverse communities in Australia (Browne \& Renzaho, 2010). This issue has been largely overlooked in research literature on online counseling to date. To address this issue, online services could provide services in languages other than English and ensure culturally sensitive services are provided, particularly given cultural differences in family and community dynamics (Reid, Crofts, \& Beyer, 2001). Issues around cultural sensitivity and accessibility are salient for both migrants to Australia and Australia's Indigenous peoples, who may require specifically tailored services in Indigenous languages, with culturally appropriate counseling provided by both Indigenous and non-Indigenous counselors depending on client preference, providing links to local Indigenousspecific treatment services (Gray et al., 2014).

Another issue facing families seeking support online was that the counseling service we studied was set up to provide brief, one-off interventions, making it difficult in some instances for families to receive the in-depth, extended counseling that many were after (see also Savic et al., 2018). Given that not all people accessing the service were seeking referral to face-to-face services, the service could be amended to increase its ability to function as a standalone service affording the various kinds of support many families were seeking (see also Rodda et al., 2015; Savic et al., 2018). This could be achieved by encouraging people to register with the service and making it possible for people to make appointments with the same counselor to allow for continuity of care. For this to take place, the funding arrangements and model of care may need to be adjusted to allow a shift from one-off engagement to longer-term care pathways.

Furthermore, family members were often experiencing a wide range of complex difficulties related both directly and indirectly to their relative's alcohol or other drug consumption (see also Orford et al., 2010b). Counselor confidence in addressing the variety of concerns and their ability to provide appropriate referrals varied. As Savic and colleagues (2018) have discussed, the ways in which online alcohol and other drug counseling is framed in policy, funding and outcome monitoring as specifically targeted at alcohol and drug concerns does not always mirror the varied issues people are seeking support for. Referrals to disparate, narrow services that only address a single issue are unable to deal with the complex issues that family members often see as interlinked with their relative's alcohol and other drug consumption (e.g., mental health and psychosocial support needs). A limited focus on referral risks losing the engagement of families with services. Although online counselors cannot be trained in all areas, having a more varied range of specialist counselors on staff may be a productive way forward. For alcohol and other drug services this could include relationship or family counselors or those who specialize in domestic violence and legal or medical issues. Although counselors at this service have received domestic violence training, in line with the Australian Government's National Plan to Reduce Violence Against Women and Their Children 2010-2022 (Council of Australian Governments, 2011), a "first door approach" should ensure that women experiencing violence are provided capable assistance at their first port of call rather than having to repeat their stories with a range of services. Where it is appropriate to provide referrals, counselors need to have accurate databases of services available beyond the service's core concern to address families' diverse needs.

In summary, our research highlighted that online counseling could enable a range of positive encounters for family members; however, its potential affordances were not always realized due to the constraints of the online platform and the ways in which the service is currently organized and funded. Our analysis suggests that several changes to the design of online counseling could improve the service provided to family members and enable it to reach a broader range of people. First, for people who prefer written communication and out of hours contact, online counseling services should be expanded as a standalone service to enable more longterm engagement and counseling rather than maintaining a focus on information, brief intervention, and referral. Second, for Indigenous Australians and culturally and linguistically diverse clients, multiple languages and culturally appropriate services are necessary. 
Third, having a varied range of specialist counselors on staff may enable services to provide support for the variety of family needs clients present with, including relationship conflict, domestic violence, supporting children, mental health, finding work, or legal or medical issues.

Finally, with the rapid evolution of multimedia capability on computers and mobile devices, online services no longer $\mathrm{n}$ to rely solely on text-based communication. As technological advancements, such as the incorporation of audio, images, and video into online chat, are more widely implemented (Barak \& Grohol, 2011), there is great potential for future iterations of online counseling to include a broader range of communication modes beyond text. Such advances may afford further engagement of those familiar with these media, particularly young people, more effective nonverbal communication of subtle affects, and avenues for those with limited written English skills. These avenues present an opportunity to explore new ways of shaping the affective atmospheres of spaces of digital health care (Lupton, 2017). Although online counseling research has focused on the efficacy of interventions, there is a paucity of research addressing the lived, embodied, affective, and sensory aspects of inhabiting online counseling spaces that needs to be addressed if we are to design desirable online spaces that afford supportive or therapeutic effects. Future research will also need to map the affordances, constraints and experiences of online counseling as it evolves with technological advancements such as automation and platform changes (Barak \& Grohol, 2011; Miner, Milstein, \& Hancock, 2017). Further experimentation with online platform design is needed to realize the possibilities of providing effective online support to families affected by a diverse range of issues, including alcohol and other drug issues in the family.

\section{Limitations and Future Directions}

There are difficulties posed by online data collection that are not necessarily present in other qualitative methods (Gregory, 2018). In this study, our sole use of online counseling transcripts limited our ability to ask questions of participants pertinent to our analytic concerns, get a sense of who was not accessing online counseling, and for those who did, the impact of their interactions beyond the session. It was not possible with these data to confirm whether people acted upon the referrals provided, or how they felt following sessions, although it could be inferred from some conversations. Future research should follow up clients after accessing online counseling services. Research could also explore the ways in which the "offline" contexts in which clients contact the service, and counselors respond, impact on online counseling encounters.

\section{Acknowledgments}

The authors thank the clients and staff of Counseling Online, especially Rick Loos and Orson Rapose.

\section{Declaration of Conflicting Interests}

The authors declared no potential conflicts of interest with respect to the research, authorship, and/or publication of this article.

\section{Funding}

The authors disclosed receipt of the following financial support for the research, authorship, and/or publication of this article: This research was funded by an Arts-Medicine Interdisciplinary Research Seed Fund grant from Monash University. Adrian Carter is supported by an NHMRC Career Development Fellowship (APP1123311). Renata Kokanović is supported by RMIT University Vice Chancellor's Senior Fellowship.

\section{ORCID iDs}

Ella Dilkes-Frayne (iD https://orcid.org/0000-0003-3113-8435 Renata Kokanović iD https://orcid.org/0000-0002-4308-3403

\section{References}

Adams, P. J. (2007). Fragmented intimacy: Addiction in a social world. New York: Springer. doi:10.1007/978-0-38772661-8

Bambling, M., King, R., Reid, W., \& Wegner, K. (2008). Online counseling: The experience of counsellors providing synchronous single-session counselling to young people. Counseling and Psychotherapy Research, 8, 110-116. doi:10.1080/14733140802055011

Barak, A., \& Bloch, N. (2006). Factors related to perceived helpfulness in supporting highly distressed individuals through an online support chat. Cyber Psychology \& Behavior, 9, 60-68. doi:10.1089/cpb.2006.9.60

Barak, A., \& Grohol, J. M. (2011). Current and future trends in internet-supported mental health interventions. Journal of Technology in Human Services, 29, 155-196. doi:10.1080/ 15228835.2011.616939

Barbour, R. S. (2001). Checklists for improving rigour in qualitative research: A case of the tail wagging the dog? British Medical Journal, 322, 1115-1117. doi:10.1136/ bmj.322.7294.1115

Bloomfield, B. P., Latham, Y., \& Vurdubakis, T. (2010) Bodies, technologies and action possibilities. Sociology, 44, 415-433. doi:10.1177/0038038510362469

Braun, V., \& Clarke, V. (2006). Using thematic analysis in psychology. Qualitative Research in Psychology, 3, 77-101. doi:10.1191/1478088706qp063oa

Browne, J. L., \& Renzaho, A. M. N. (2010). Prevention of alcohol and other drug problems in culturally and linguis- 
tically diverse communities. Prevention Issues Quarterly: Druginfo Clearinghouse, 13, 1-24.

Chardon, L., Bagraith, K. S., \& King, R. (2011). Counseling activity in single-session online counseling with adolescents: An adherence study. Psychotherapy Research, 21, 583-592. doi:10.1080/10503307.2011.592550

Chemero, A. (2003). An outline of a theory of affordances. Ecological Psychology, 15, 181-195. doi:10.1207/ S15326969ECO1502 5

Copeland, J., \& Martin, G. (2004). Web-based interventions for substance use disorders: A qualitative review. Journal of Substance Abuse Treatment, 26, 109-116. doi:10.1016/ S0740-5472(03)00165-X

Copello, A., \& Orford, J. (2002). Addiction and the family: Is it time for services to take notice of the evidence? Addiction, 97, 1361-1363. doi:10.1046/ j.1360-0443.2002.00259.x

Copello, A., \& Templeton, L. (2012). The forgotten carers: Support for adult family members affected by a relative's drug problems. London: UK Drug Policy Consortium.

Council of Australian Governments. (2011). National plan to reduce violence against women and their children 20102022. Canberra: Council of Australian Governments.

Davis, J.L., \& Chouinard, J. B. (2017). Theorizing affordances: From request to refuse. Bulletin of Science, Technology \& Society, 36, 241-248. doi:10.1177/027046761771 4944

Day, S., \& Schneider, P. (2002). Psychotherapy using distance technology: A comparison of face-to-face, video, and audio treatment. Journal of Counselling Psychology, 49, 499503. doi:10.1037//0022-0167.49.4.499

Dowling, M., \& Rickwood, D. (2013). Online counseling and therapy for mental health problems: A systematic review of individual synchronous interventions using chat. Journal of Technology in Human Services, 31(1), 1-21. doi:10.1080/1 5228835.2012.728508

Fraser, S., Treloar, C., Gendera, S., \& Rance, J. (2017). "Affording" new approaches to couples who inject drugs: A novel fitpack design for Hepatitis C prevention. International Journal of Drug Policy, 50, 19-35. doi:10.1016/j.drugpo.2017.07.001

Frye, S., Dawe, S., Harnett, P., Kowalenko, S., \& Harlen, M. (2008). Supporting the families of young people with problematic drug use: Investigating support options. Canberra: Australian National Council on Drugs.

Gainsbury, S., \& Blaszczynski, A. (2011). A systematic review of internet-based therapy for the treatment of addictions. Clinical Psychology Review, 31, 490-498. doi:10.1016/j. cpr.2010.11.007

Garde, E. L., Manning, V., \& Lubman, D. I. (2017). Characteristics of clients currently accessing a national online alcohol and drug counselling service. Australian Psychiatry, 25, 250-253. doi:10.1177/1039856216689623

Gibson, J. J. (1979). The ecological approach to visual perception. Boston: Houghton Mifflin Harcourt.

Gray, D., Wilson, M., Allsop, S., Saggers, S., Wilkes, E., \& Ober, C. (2014). Barriers and enablers to the provision of alcohol treatment among Aboriginal Australians: A the- matic review of five research projects. Drug \& Alcohol Review, 33, 482-490.

Gregory, K. (2018). Online communication settings and the qualitative research process: Acclimating students and novice researchers. Qualitative Health Research, 28, 16101620. doi:10.1177/1049732318776625

Hutchby, I. (2001). Technologies, texts and affordances. Sociology, 35, 441-456. doi:10.1017/S0038038501000219

King, R., Bambling, M., Lloyd, C., Gomurra, R., Smith, S., Reid, W., \& Wegner, K. (2006). Online counselling: The motives and experiences of young people who choose the Internet instead of face to face or telephone counselling. Counselling and Psychotherapy Research, 6, 169-174. doi:10.1080/14733140600848179

Klinke, M. E., Thorsteinsson, B., \& Jónsdóttir, H. (2014). Advancing phenomenological research: Applications of "body schema," "body image," and "affordances" in neglect. Qualitative Health Research, 24, 824-836. doi:10.1177 /1049732314533425

Lupton, D. (2017). How does health feel? Towards research on the affective atmospheres of digital health. Digital Health, 3, 1-11. doi:10.1177/2055207617701276

McCann, T. V., \& Lubman, D. I. (2017a). Adaptive coping strategies of affected family members of a relative with substance misuse: A qualitative study. Journal of Advanced Nursing, 74, 100-109. doi:10.1111/jan.13405

McCann, T. V., \& Lubman, D. I. (2017b). Stigma experience of families supporting an adult family member with substance misuse. International Journal of Mental Health Nursing, 27, 693-701. doi:10.1111/inm.12355

McCann, T. V., Lubman, D. I., Boardman, G., \& Flood, M. (2017). Affected family members' experience of, and coping with, aggression and violence within the context of problematic substance use: A qualitative study. BMC Psychiatry, 17, Article 209. doi:10.1186/s12888-017-1374-3

Miller, W. R., \& Rollnick, S. (1991). Motivational interviewing: Preparing people to change addictive behavior. New Work: Guilford Press. doi:10.1002/casp.2450020410

Miner, A. S., Milstein, A., \& Hancock, J. T. (2017). Talking to machines about personal mental health problems. Journal of the American Medical Association, 318, 1217-1218. doi:10.1001/jama.2017.14151

Misouridou, E., \& Papadatou, D. (2017). Challenges in engaging parents in the drug and alcohol treatment: The professionals' perspective. Qualitative Health Research, 27, 1948-1958. doi:10.1177/1049732316673582

Norman, D. A. (1988). The psychology of everyday things. New York: Basic Books.

O'Grady, C., \& Skinner, W. J. W. (2015). Using virtual space to provide group support and education to families affected by concurrent disorders. European Psychiatry, 30(Supp1), 1666. doi:10.1016/S0924-9338(15)32087-3

O’Grady, C. P., \& Skinner, W. J. W. (2012). Journey as destination: A recovery model for families affected by concurrent disorders. Qualitative Health Research, 22, 1047-1062. doi:10.1177/1049732312443736

Orford, J., Copello, A., Velleman, R., \& Templeton, L. (2010a). Family members affected by a close relative's addiction: 
The stress-strain-coping-support model. Drugs: Education, Preventions and Policy, 17(S1), 36-43. doi:10.3109/09687 637.2010.514801

Orford, J., Velleman, R., Copello, A., Templeton, L., \& Ibanga, A. (2010b). The experiences of affected family members: A summary of two decades of qualitative research. Drugs: Education, Preventions and Policy, 17(S1), 44-62. doi:10. 3109/09687637.2010.514192

Reid, G., Crofts, N., \& Beyer, L. (2001). Drug treatment services for ethnic communities in Victoria, Australia: An examination of cultural and institutional barriers. Ethnicity \& Health, 6, 13-26. doi:10.1080/13557850124373

Richards, D., \& Viganó, N. (2013). Online counseling: A narrative and critical review of the literature. Journal of Clinical Psychology, 69, 994-1011. doi:10.1002/jclp.21974

Rodda, S. N., Lubman, D. I., Cheetham, A., Dowling, N. A., \& Jackson, A. C. (2015). Single session web-based counselling: A thematic analysis of content from the perspective of the client. British Journal of Guidance \& Counselling, 43, 117-130. doi:10.1080/03069885.2014.938609

Rodda, S. N., Lubman, D. I., Dowling, N. A., Bough, A., \& Jackson, A. C. (2013a). Web-based counseling for problem gambling: Exploring motivations and recommendations. Journal of Medical Internet Research, 15(5), e99. doi:10.2196/jmir.2474

Rodda, S. N., Lubman, D. I., Dowling, N. A., \& McCann, T. V. (2013b). Reasons for using web-based counselling among family and friends impacted by problem gambling. Asian Journal of Gambling Issues and Public Health, 3, Article 12. doi:10.1186/2195-3007-3-12

Savic, M., Dilkes-Frayne, E., Carter, A., Kokanović, R., Manning, V., \& Lubman, D. I. (2018). Making multiple "online counsellings" through policy and practice: An evidence-making intervention approach. International Journal of Drug Policy, 53, 73-82. 10.1016/j.drugpo.2017.12.008

Savic, M., Ferguson, N., Manning, V., Bathish, R., \& Lubman, D. I. (2017). "What constitutes a 'problem'?" Producing "alcohol problems" through online counselling encounters. International Journal of Drug Policy, 46, 79-89. doi:10.1016/j.drugpo.2017.05.047

Stommel, W., \& van der Houwen, F. (2014). Complaining and the management of face in online counselling. Qualitative Health Research, 24, 183-193. doi:10.1177/1049732313 519706

Sucala, M., Schnur, J. B., Constantino, M. J., Miller, S. J., Brackman, E. H., \& Montgomery, G. H. (2012). The therapeutic relationship in e-therapy for mental health: A systematic review. Journal of Medical Internet Research, 14(4), e110. doi:10.2196/jmir.2084

Swan, A. J., \& Tyssen, E. G. (2009). Enhancing treatment access: Evaluation of an Australian web-based alcohol and drug counselling initiative. Drug \& Alcohol Review, 28, 48-53. doi:10.1111/j.1465-3362.2008.00006.x

Wagner, V., Bertrand, K., Flores-Aranda, J., Acier, D., Brunelle, N., Landry, M., \& Brouchu, S. (2017). Initiation of addiction treatment and access to services: Young adults' accounts of their help-seeking experiences. Qualitative Health Research, 27, 1614-1627. doi:10.1177/1049732316679372

Williams, R., Bambling, M., King, R., \& Abbott, Q. (2009). In-session processes in online counselling withyoung people: An exploratory approach. Counselling and Psychotherapy Research, 9, 93-100. doi:10.1080/14733140802490606

Wilson, S. R., Lubman, D. I., Rodda, S., Manning, V., \& Yap, M. B. H. (2017a). The personal impacts of having a partner with problematic alcohol or other drug use: Descriptions from online counselling sessions. Addiction Research \& Theory, 26, 315-322. doi:10.1080/16066359.2017.13743 75

Wilson, S. R., Rodda, S., Lubman, D. I., Manning, V., \& Yap, M. B. H. (2017b). How online counselling can support partners of individuals with problem alcohol or other drug use. Journal of Substance Abuse Treatment, 78, 56-62. doi:10.1016/j.jsat.2017.04.009

\section{Author Biographies}

Ella Dilkes-Frayne is a research officer in the School of Sociology, Research School of Social Sciences, Australian National University, and was previously a Research Fellow in the Neuroscience and Society Group, Monash Institute of Cognitive and Clinical Neurosciences, Monash University. Ella's research focuses on alcohol and drug use, drug policy and programs, and concepts of addiction.

Michael Savic is a senior research fellow (Addiction Studies) at Monash University and Strategic Lead of Clinical and Social Research at Turning Point, Eastern Health. Michael's research focuses on alcohol and other drug use, addiction concepts, the implementation of interventions, and experiences care across a number of mediums.

Adrian Carter is an NHMRC Career Development Fellow and Head, Neuroscience and Society Group, Monash Institute of Cognitive and Clinical Neurosciences, Monash University. He is Director, Neuroethics Program, ARC Centre of Excellence for Integrative Brain Function and Co-Chair, Neuroethics and Responsible Research and Innovation Committee, Australian Brain Alliance. Dr Carter has been an advisor to the WHO, European Monitoring Centre for Drugs and Drug Addiction, and United Nations Office on Drugs and Crime.

Renata Kokanović, $\mathrm{PhD}$, is a professor of Sociology of Health and Illness at RMIT University in Melbourne and Director of Healthtalk Australia. Renata leads the Health and Society Research Program which generates critical understandings of lived experience of health and illness in diverse sociocultural contexts.

Dan I. Lubman is a psychiatrist and addiction medicine specialist. He is Director of Turning Point, Australia's national addiction treatment, training and research centre, and Professor of Addiction Studies and Services at Monash University. 